\title{
Cervical Pedicle Screw Fixation: Anatomic Feasibility of Pedicle Morphology and Radiologic Evaluation of the Anatomical Measurements
}

\author{
Mohamed M Mohi Eldin \\ Department of Neurosurgery, Faculty of Medicine, Cairo University, Giza, Egypt
}

\begin{abstract}
Study Design: All parameters were measured manually and with a computed tomography (CT) scanner. For the manual measurements, a Vernier scale instrument was used.

Purpose: This study evaluates quantitatively pedicles of middle and lower cervical spine $\left(C_{3}\right.$ to $\left.C_{7}\right)$ and to evaluate the possibilities of using these structures as anchors in posterior cervical fusion.

Overview of literature: Pedicle screws may be an alternative fixation technique for posterior cervical instrumentation.

Methods: Twenty-two bony sets of adult cervical spines were studied (110 vertebrae, 220 pedicles) from $\mathrm{C}_{3}$ down to $\mathrm{C}_{7}$.

Results: CT measurement of cervical pedicles appeared to be accurate and valuable for preoperative planning of cervical pedicle screw instrumentation. The study showed a high correlation between the values obtained by manual and CT measurements of pedicle dimensions. The technical challenge of insertion is the obvious theoretical drawback of the use of cervical pedicle screws. Many technical factors are important to consider, namely, the point of screw entry, the pedicle dimensions, the screw direction according to the pedicle angle and orientation, the screw diameter and length, and the method of screw introduction.

Conclusions: Transpedicular screw fixation of the cervical spine appears to be promising. Anatomic limitations should be clear to the surgeon. Further clinical and biomechanical studies are needed to settle this technique.
\end{abstract}

Keywords: Spine; Morphology; Screw; Pedicle

\section{Introduction}

Posterior cervical fixation techniques have been proven to be an effective means of stabilization in the cervical spine. For most types of cervical instability, screw fixation techniques provide superior fixation to interspinous wiring, especially in the absence or deficiency of spinous processes and in multilevel instabilities [1,2].

To date, the lateral mass has been the preferred site of screw placements for posterior cervical fixation [3].
Although the lateral mass screws have been proven to be relatively safe despite of their proximity to the vertebral arteries, cranial nerve roots, and spinal cord, they have inherent biomechanical limitations because of the small amounts of bony purchases available for those areas. The most common is screw loosening or avulsion especially in the upper and lower cervical vertebrae where the lateral masses are typically diminutive with low pullout resistances [4]. Therefore, the pedicle screws may be an alternative fixation technique for posterior cervical fixation.

Received Jun 13, 2013; Revised Jul 12, 2013; Accepted Jul 14, 2013

Corresponding author: Mohamed M. Mohi Eldin

Department of Neurosurgery, Faculty of Medicine, Cairo University, Cairo, Egypt

Tel: +20-1227342964, Fax: +20-233022907, E-mail: mmohio63@yahoo.com 
In 1994, Abumi et al. [5] was the first to introduce screws into the pedicles in the lower cervical spine in order to manage fractures and dislocations, followed by Jeanneret et al. [6]. Later, Abumi and Kaneda [7,8] reported a large number of patients who underwent transpedicular fixations for the treatment of unstable cervical spine caused by trauma, tumors, infections, degenerative conditions and failed anterior fusions, with a higher fusion rate and no complications except for one patient who developed transient postoperative radiculopathy.

\section{Study objective}

The objective of this study is to evaluate quantitatively the pedicles from $\mathrm{C} 3$ to $\mathrm{C} 7$, and to evaluate the possibilities of using the structures as anchors in posterior fusion of the cervical spine (Fig. 1).

\section{Materials and Methods}

\section{Study idea and description}

Twenty-two normal adult human bony sets of spines containing all C3-C7 vertebrae (total of 110 vertebrae, or 220 pedicles) from the Anatomy Department and Museum of Cairo University were used for this project. None of the used vertebrae had evidences of infectious, neoplastic, traumatic or degenerative diseases, and we found no evidences of congenital or developmental spinal malformations in any of the specimens. The chosen adult vertebrae

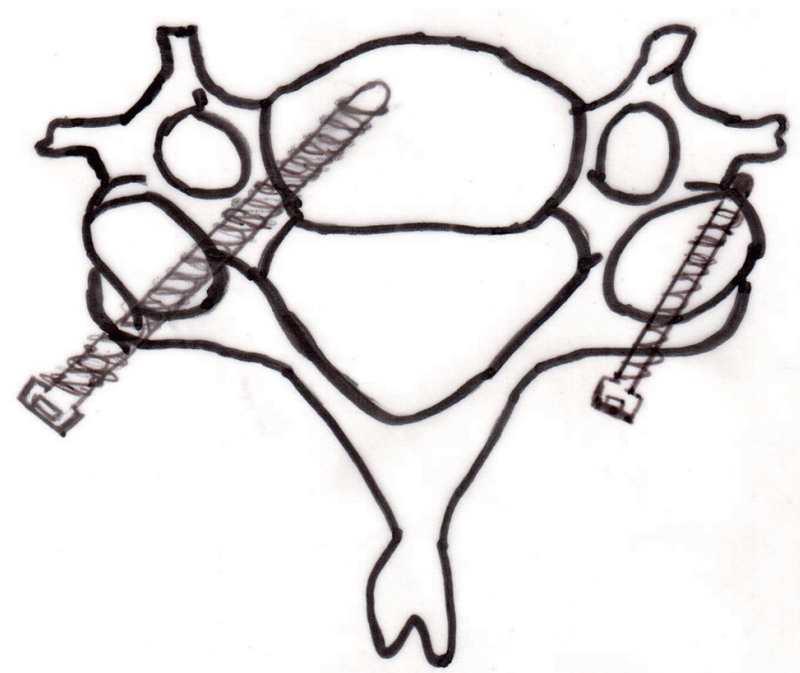

Fig. 1. Diagram of lateral mass and pedicle screws of a cervical vertebra showing different positions. minimize the effects of growth and aging on the collected data (Figs. 2, 3).

All parameters were measured manually and also with a computed tomography (CT) scanner. For manual measurements, the Vernier scale instrument was used. The appropriate measuring site for every parameter, as well as the accuracy of measurement was determined by the authors.

By using the multislice CT scanner with sagittal, coronal and three-dimensional reconstruction images, measurements of pedicles were performed by an experienced radiologist. The authors went through all the recorded data and checked the accuracy of the measurements (Figs. 4-6).

\section{Measurements}

1) Linear parameters

Cervical pedicle morphology was evaluated by measure-

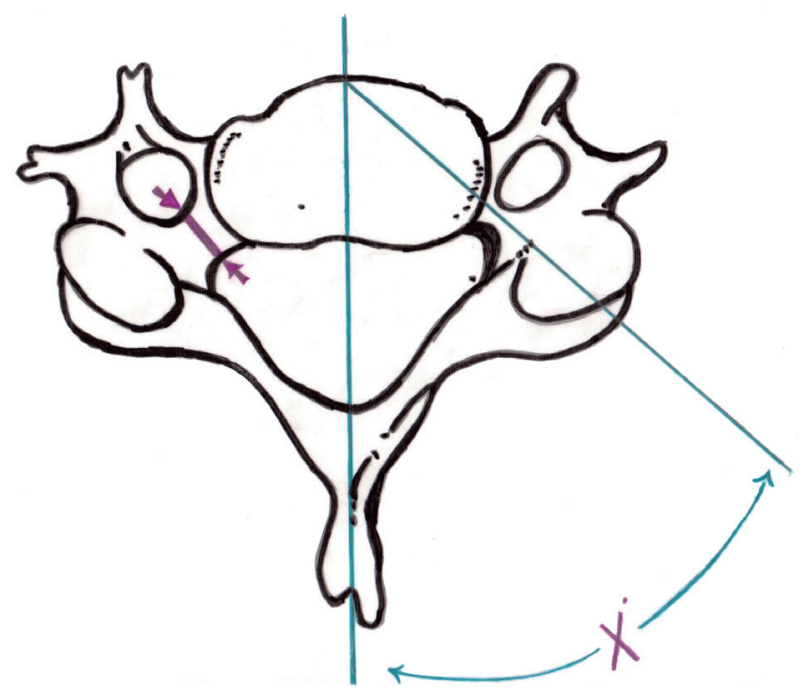

Fig. 2. Pedicle angle and pedicle width.

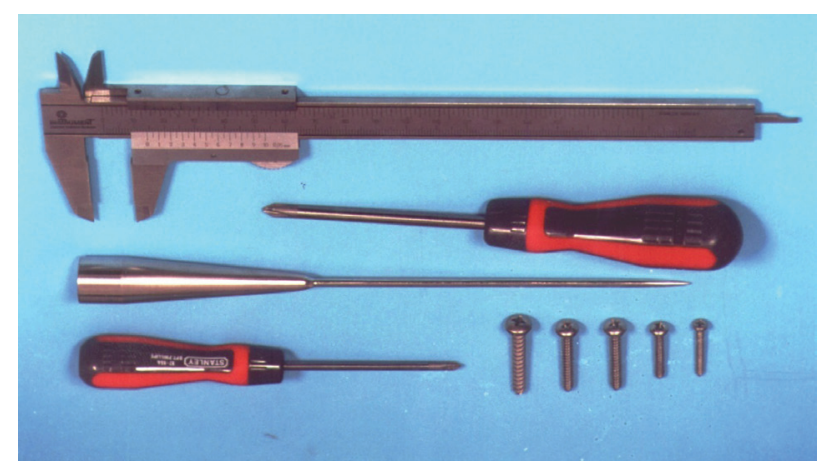

Fig. 3. Instruments and screws used in the study. 
ments of the following linear parameters (all paired structures were measured on each side):

- Pedicle width (medio-lateral diameter of the pedicle isthmus),

- Pedicle height (supero-inferior diameter of the pedi-

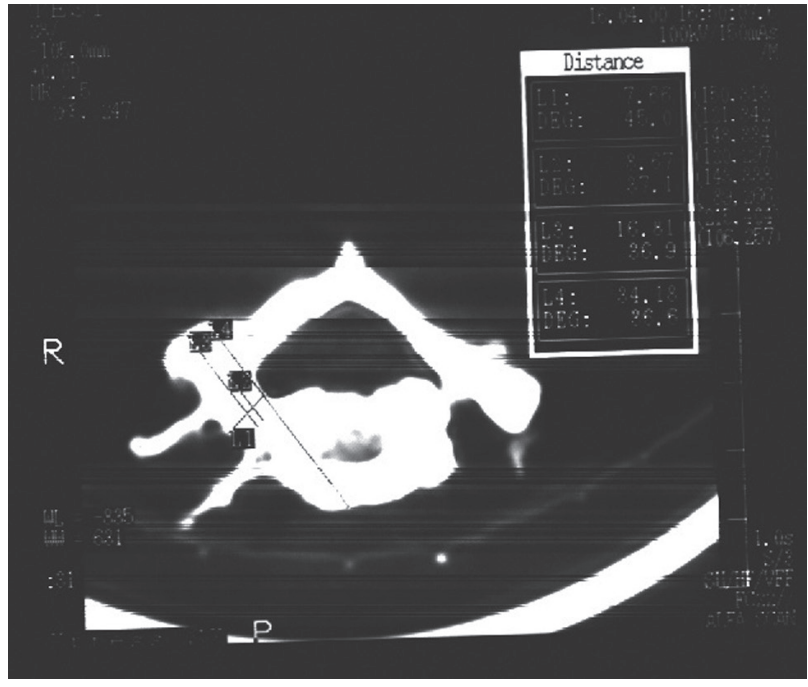

Fig. 4. Computed tomography measurement of linear parameters.

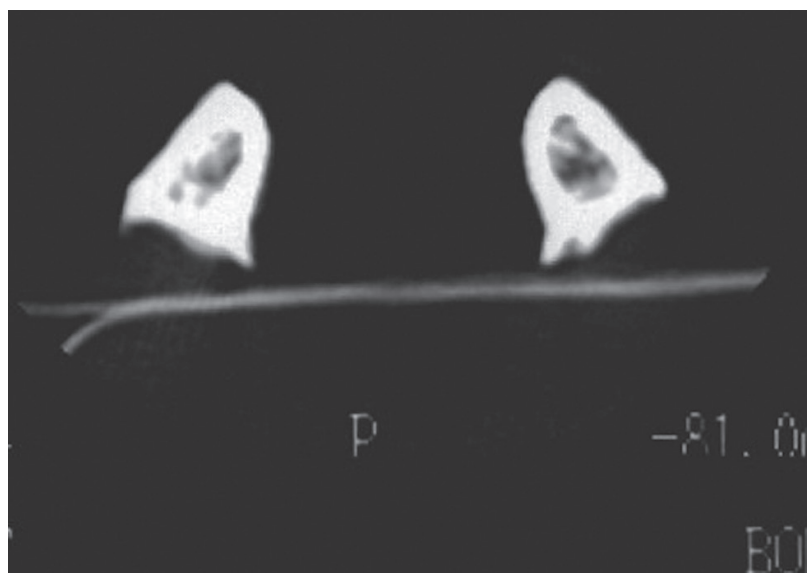

Fig. 5. Computed tomography cut section showing pedicle dimensions.

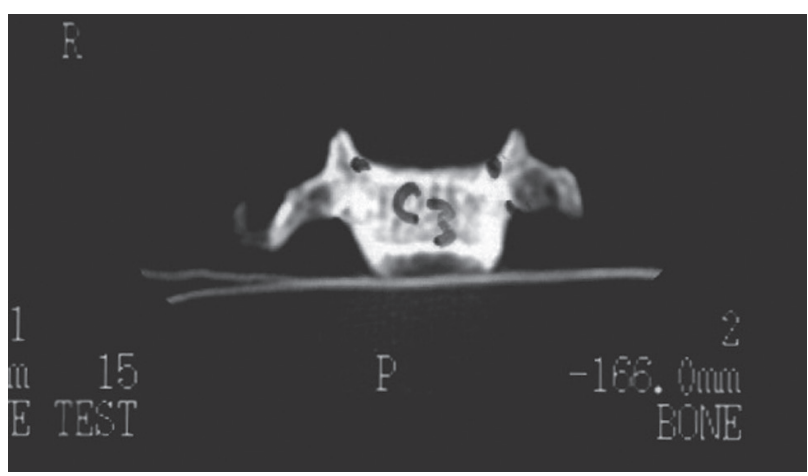

Fig. 6. Computed tomography measurement of pedicle height. cle isthmus),

- Pedicle length (distance between the lateral mass and the vertebral body),

- Lateral mass-pedicle length (distance between the posterior point of the pedicle axis projection on the lateral mass and the vertebral body),

- Pedicle axis length (distance between the posterior point of pedicle axis projection and the anterior-most point of the pedicle axis projection).

2) Medial inclination of the pedicles (pedicle angle) In the horizontal plane, the angle between the pedicle axis and a line perpendicular to the vertebral body cortex.

\section{Screws used in the study}

After using the appropriate tap, a cortical screw (2-7 to 4.5 $\mathrm{mm}$ ) was inserted into the pedicle.

Based on the works of Heller et al. [4], the $3.5 \mathrm{~mm}$ cortical screw provided superior fixation in the lateral masses when compared with a variety of cortical and cancellous screws ranging from 2.7 to $4.5 \mathrm{~mm}$ in diameter. However, Jones et al. [9] found no significant difference in the pullout strength of $2.7 \mathrm{~mm}$ and $3.5 \mathrm{~mm}$ pedicle screws. So, in this study, when the outer diameter of the pedicle was $<5.0 \mathrm{~mm}$, a $2.7 \mathrm{~mm}$ cortical screw was used instead of the 3.5 screw. The screw length was defined as the mms of thread engaging bone (i.e., actual working screw length).

Pedicle cortical wall violations, by screws, were recorded as minor or major violations. Minor violations were mostly defined as only minor plastic deformations of the pedicle cortex, or screw threads or less than one-fourth of the screw cross section penetrating the cortex. Major violations were defined as more than one-fourth of the screw cross section penetrating the cortex.

\section{Results}

The mean pedicle width at C3 ranged from 6.2 to $6.8 \mathrm{~mm}$. At C4, it ranged from 6.2 to $6.9 \mathrm{~mm}$. At C5, it ranged from 6.5 to $7.5 \mathrm{~mm}$. At C6, it ranged from 6.2 to $7.0 \mathrm{~mm}$. At C7, it ranged from 6.1 to $6.9 \mathrm{~mm}$ (Table 1).

The mean pedicle height ranged from $4.6 \mathrm{~mm}$ at $\mathrm{C} 3$ to $4.9 \mathrm{~mm}$. At C4, it ranged from 4.6 to $5.0 \mathrm{~mm}$. At C5, it ranged from 4.7 to $5.5 \mathrm{~mm}$. At C6, it ranged from 5.5 to 6.9 $\mathrm{mm}$. At C7, it ranged from 6.0 to $6.9 \mathrm{~mm}$. Thus, cervical pedicles tend to be longer than the width (Table 2). 
Table 1. Pedicle height (superior inferior diameter)

\begin{tabular}{lcc} 
Vertebra & $\begin{array}{c}\text { Range of manual } \\
\text { and radiological } \\
\text { measurement }(\mathrm{mm})\end{array}$ & $\begin{array}{c}\text { Range of } \\
\text { measurement of } \\
\text { other studies }(\mathrm{mm}) \\
{[5,9,10]}\end{array}$ \\
C3 & $6.2-6.8$ & $6.2-7.4$ \\
C4 & $6.2-6.9$ & $6.8-7.7$ \\
C5 & $6.5-7.5$ & $6.6-7.7$ \\
C6 & $6.2-7.0$ & $6.5-7.4$ \\
C7 & $6.1-6.9$ & $5.9-6.7$ \\
\hline
\end{tabular}

Table 2. Pedicle width (mediolateral diamter)

\begin{tabular}{lcc} 
Vertebra & $\begin{array}{c}\text { Mean range of manual } \\
\text { and radiological } \\
\text { measurements }(\mathrm{mm})\end{array}$ & $\begin{array}{c}\text { Range of } \\
\text { measurements of } \\
\text { other studies }(\mathrm{mm}) \\
{[5,9,10]}\end{array}$ \\
\hline C3 & $4.3-4.9$ & $4.5-5.3$ \\
C4 & $4.6-5.0$ & $4.5-5.4$ \\
C5 & $4.7-5.5$ & $5.0-5.7$ \\
C6 & $5.5-6.9$ & $5.0-5.9$ \\
C7 & $6.0-6.9$ & $5.9-6.7$ \\
\hline
\end{tabular}

Table 3. Pedicle length

\begin{tabular}{lcc} 
Vertebra & $\begin{array}{c}\text { Mean range of manual } \\
\text { and radiological } \\
\text { measurements }(\mathrm{mm})\end{array}$ & $\begin{array}{c}\text { Range of } \\
\text { measurements of } \\
\text { other studies }(\mathrm{mm}) \\
{[5,9,10]}\end{array}$ \\
\hline C3 & $5.9-6.6$ & $5.9-6.7$ \\
C4 & $6.0-7.7$ & $5.8-7.5$ \\
C5 & $6.5-7.8$ & $6.4-8.0$ \\
C6 & $7.2-8.8$ & $7.0-8.3$ \\
C7 & $7.3-10.0$ & $7.0-8.4$ \\
\hline
\end{tabular}

Table 4. Lateral mass-pedicle length

\begin{tabular}{lcc} 
Vertebra & $\begin{array}{c}\text { Mean range of manual } \\
\text { and radiological } \\
\text { measurements }(\mathrm{mm})\end{array}$ & $\begin{array}{c}\text { Range of } \\
\text { measurements of } \\
\text { other studies }(\mathrm{mm}) \\
{[5,9,10]}\end{array}$ \\
\hline C3 & $16.1-16.9$ & $16.3-16.3$ \\
C4 & $15.5-16.3$ & $15.5-16.3$ \\
C5 & $15.1-15.9$ & $15.4-16.3$ \\
C6 & $16.8-17.9$ & $14.8-15.5$ \\
C7 & $16.5-20.0$ & $13.6-14.5$ \\
\hline
\end{tabular}

Table 5. Pedicle-axis length

\begin{tabular}{lcc} 
Vertebra & $\begin{array}{c}\text { Mean range of manual } \\
\text { and radiological } \\
\text { measurements }(\mathrm{mm})\end{array}$ & $\begin{array}{c}\text { Range of } \\
\text { measurements of } \\
\text { other studies }(\mathrm{mm}) \\
{[5,9,10]}\end{array}$ \\
C3 & $30.0-32.3$ & $32.7-30.5$ \\
C4 & $31.9-33.3$ & $30.3-32.5$ \\
C5 & $30.8-36.8$ & $30.5-32.4$ \\
C6 & $30.5-34.2$ & $30.2-31.5$ \\
C7 & $29.5-36.5$ & $29.5-30.8$ \\
\hline
\end{tabular}

Table 6. Radiological analyses of the patterns of failure in relation to the cause of instability

\begin{tabular}{lcc} 
Vertebra & $\begin{array}{c}\text { Mean range of manual } \\
\text { and radiological } \\
\text { measurements }\left({ }^{\circ}\right)\end{array}$ & $\begin{array}{c}\text { Range of } \\
\text { measurements of } \\
\text { other studies }\left({ }^{\circ}\right) \\
{[5,9,10]}\end{array}$ \\
C3 & $37-47$ & 46 \\
C4 & $33-45$ & 46 \\
C5 & $40-52$ & 46 \\
C6 & $37-42$ & 45 \\
C7 & $41-44$ & 39 \\
\hline
\end{tabular}

The mean pedicle length ranged at $\mathrm{C} 3$ from 5.9 to 6.6 $\mathrm{mm}$, at C4 from 6.0 to $7.7 \mathrm{~mm}$, at C5 from 6.5 to $7.5 \mathrm{~mm}$, at C6 from 7.2 to $8.8 \mathrm{~mm}$, and at C7 from 7.3 to $10.0 \mathrm{~mm}$ (Table 3).

The mean lateral mass-pedicle length ranged at $\mathrm{C} 3$ from 16.1 to $16.9 \mathrm{~mm}$, at C4 from 15.5 to $16.3 \mathrm{~mm}$, at C5 from 15.1 to $15.9 \mathrm{~mm}$, at C6 from 16.8 to $17.9 \mathrm{~mm}$, and at C7 from 16.5 to $20.0 \mathrm{~mm}$ (Table 4 ).

The mean pedicle axis length ranged at $\mathrm{C} 3$ from 30.0 to $32.3 \mathrm{~mm}$, at C4 from 31.9 to $33.3 \mathrm{~mm}$, at C5 from 30.8 to $36.8 \mathrm{~mm}$, at C6 from 30.5 to $34.2 \mathrm{~mm}$, and at C7 from 29.5 to $36.5 \mathrm{~mm}$ (Table 5 ).

All the measured pedicle length, lateral mass-pedicle length and pedicle axis length showed similar values in all cervical specimens.

The mean medial angulation of the pedicles in this study ranged from $37^{\circ}$ to $47^{\circ}$ at $\mathrm{C} 3$, from $33^{\circ}$ to $45^{\circ}$ at $\mathrm{C} 4$, from $40^{\circ}$ to $52^{\circ}$ at $\mathrm{C} 5$, from $37^{\circ}$ to $42^{\circ}$ at C6 and from $41^{\circ}$ to $47^{\circ}$ at $\mathrm{C7}$ (Table 6).

Although no direct measurements were taken in the sagittal plane, the orientations of pedicle screws were found to be generally parallel to the vertebral body end 
Table 7. Reported cortical wall violation of the pedicle by screws

\begin{tabular}{|c|c|c|c|c|}
\hline \multirow{2}{*}{ Series } & \multirow{2}{*}{ No. of materials } & \multicolumn{2}{|c|}{ Minor violations } & \multirow{2}{*}{ Major violations } \\
\hline & & No. & $\%$ & \\
\hline Jeanneret et al. [6], cadaveric study (1994) & 33 Pedicles (fresh cadavers) & 10 & 30.3 & 0 \\
\hline Abumi et al. [7], clinical series (1995) & 13 Patients & 4 & $<10$ & 0 \\
\hline Jones et al. [9], cadaveric study (1997) & 92 Pedicles (fresh cadavers) & 7 & 13 & 0 \\
\hline The present anatomical study & 220 Pedicles (dry bony vertebrae) & 24 & 10.9 & 0 \\
\hline
\end{tabular}

plates.

Pedicle cortical wall violations were recorded. Minor violations were found in 24 dry-tapped pedicles representing about $10.9 \%$ of the tapped pedicles. Major violations involving more than one-fourth of the screw cross section penetrating the cortex, were not reported (Table 7).

\section{Discussion}

Transpedicular screw fixation systems in the thoracic and lumbar spine, showed excellent stability and strength, allowing the patient to walk immediately after surgery. Exact knowledge of the anatomy of the pedicles and careful surgical techniques made their placements rather safe, despite the theoretical risks perceived.

In the middle and lower cervical spines, transpedicular screw fixation has not yet been performed for the fear of injury on the vertebral artery, spinal cord and nerve roots. Roy-Camille et al. [10] stated that screwing into C3 to $\mathrm{C} 6$ pedicle would be an unacceptable risk. However, the pedicel of the cervical spine is a strong structure of the vertebra, similar to the thoracic and lumbar spine.

In the cervical spine, the cortex of the vertebral bodies is not as strong as that of the posterior elements. Thus, in the anterior cervical plate fixation, even if the screws penetrate the posterior cortex of the vertebral body, it does not provide sufficient posterior fixation procedures due to failed cases of posterior elements or combined anterior and posterior failures. Additional use of posterior instrumentations on anterior cervical plates may be recommended [11,12].

Moreover, in combined anterior and posterior failures of cervical stability, the biomechanical studies showed that neither the spinous process wiring, posterior platting, Luque segmental spinal instrumentation nor other available techniques provided adequate stability $[11,12]$.
In addition, biomechanical studies of lateral mass posterior plate fixation done by Gill et al. [13], and Montesano et al. [14], showed that bicortical screws were more stabilizing than unicortical screws. However, bicortical screws stiffness did not exceed that of spinous process wiring. In addition, screw insertion into the lateral portion of the articular mass exposes the spinal nerves or vertebral artery to injury $[13,14]$, and sublaminar wires expose the spinal cord to injury in stenotic canals.

In 1994, Jeanneret et al. [6] reported anatomic and clinical results with transpedicular screw fixation using 4.0 $\mathrm{mm}$ cancellous screws. Though limited to three patients, the 7 year follow-up was favorable with no complications. In the same year, Abumi et al. [5] successfully used cervical pedicle screws modified with $4.5 \mathrm{~mm}$ diameter variable screw placement (VSP) screws of a modified VSP plate (AcroMed, Clevland, OH, USA). They reported that a smaller screw size is sometimes necessary; $3.5 \mathrm{~mm}$, $4.0 \mathrm{~mm}$ and $4.5 \mathrm{~mm}$ cancellous screws were used from $\mathrm{C} 2$ to $\mathrm{T} 1$ for reconstruction or stabilization of a variety of pathologic lesions. Later on, in the same year, Kotani et al. [2], reported a biomechanical study showing that this method of fixation had stiffness that was equal to or greater than that of lateral mass plates, especially in more than one levels affection and supported such use. In 1997, in a biomechanical study, Jones et al. [9] found that pedicle screws sustain a significantly higher axial load-tofailure than the lateral mass screws in the human cervical spine; thus, providing superior fixation for posterior platting and reducing the possibility of hardware loosening. Lastly, in 1999, Xu et al. [15], also reported that patients with osteoporosis or requires three-column reconstructions of the cervical spine may benefit from transpedicular screw fixation.

Many anatomical studies focused on the cervical spine pedicles as anchors for screw placement. Pech et al. [16] reported the relation of the cervical nerve roots in the 
Table 8. Anatomical studies of pedicles in the cervical spine

\begin{tabular}{|c|c|c|c|}
\hline Study & Year & No. of sets & Aim \\
\hline Pal and Routal [18] & 1986 & 44 Adult cervical columns & $\begin{array}{l}\text { Measured some pedicle parameters in selected vertebrae } \\
(\mathrm{C} 2, \mathrm{C} 4, \mathrm{C} 6, \mathrm{C} 7)\end{array}$ \\
\hline Panjabi et al. [17] & 1991 & 12 Fresh autopsy spines & Measured pedicle dimensions using special morphometers. \\
\hline Karaikovic et al. [19] & 1997 & 53 Normal human cadaveric spines & $\begin{array}{l}\text { Measured pedicle linear data and inclinations both manually } \\
\text { and using computed tomography measurements. }\end{array}$ \\
\hline
\end{tabular}

neural foramina. The roots run anterolaterally at $45^{\circ}$ in the coronal plane. They also run in the inferior half of the neural foramina at and below the disc level. Thus, there is some room between the medial and inferior surface of the pedicle and the nerve roots. Slight perforations of the pedicle by screw threads in the medial or inferior direction are relatively safe. Xu et al. [15] whom also studied pedicle relations, observed that there was no space between the medial and superior walls of pedicle and dural sac and adjacent nerve root, respectively. A little space, after Xu et al. [15], does exist between the inferior wall of the pedicle and adjacent nerve root, with a range of 1.4-1.6 mm. According to Abumi et al.'s study [5] medial wall violations are higher than others, but there were no nerve involvements. In his study, he reported 4 minor violations ( 3 medial and one inferior) with no clinical complications. Jeanneret et al. [6] reported 10 minor and no major cortical wall violations. Jones et al. [9] reported $13 \%$ minor violations with no clinical complications. They pointed out the need for an individualized approach to the transpedicular screw placement, due to the variability in pedicle dimensions and orientations. In our study, there were 24 minor violations (10.9\%) with no major violations. Eighteen minor violations involved the foramen transversarium and 6 involved the spinal canal. Thus, all pedicle wall violations occurred medially or laterally, which presented similar results as those of Jones et al. [9]. No superior or inferior wall violations were noted. All violations slightly exposed the screw threads. These minor violations would have resulted in significant clinical sequelae which is a matter of speculations. All the reported surgical and clinical studies showed that they were either insignificant or caused transient reversible clinical sequelae. Abumi et al. [5] reported that the main cause of screw penetration for pedicles was the maladaptation between the screw and pedicle diameter. The reported neurological complications incidence seems to be low and comparable with the data of lateral mass fixations [15].
Because of the small depth of the pedicle in the cervical spine of this study, with a range of $5.9 \mathrm{~mm}$ to $10.0 \mathrm{~mm}$, the direction of the screw insertion is not severely restricted.

This study, together with previous studies, as in $\mathrm{Xu}$ et al. [15], supported the anatomical finding that statistical significant differences existed between the pedicle dimensions at different levels of cervical vertebrae. In the present study, the mean pedicle height was greatest at the C5 level with little decreases for up and down levels. However, cervical pedicles tend to be longer than the width. The minimum pedicle width and height was observed at C3. Correspondingly, Panjabi et al. [17], Abumi and Kaneda [8] and Jones et al. [9] found similar results. These findings are supported by the fact that all minor pedicle wall violations in this study occurred either medially or laterally, mainly at the level of C3. According to these findings, the $4.0 \mathrm{~mm}$ and $4.5 \mathrm{~mm}$ cancellous screws used in the previously mentioned studies by Jeanneret et al. [6], and Abumi et al. [5] seems to be large for the safe use in all specimens (Table 8) [17-19]. Our policy for the selection of used screws, which was similar to that of Jones et al. [9], was more or less safe. The $3.5 \mathrm{~mm}$ cortical screw was preferred, based on the works of Heller et al. [4], except when the outer diameter of the pedicle was less than $0.5 \mathrm{~mm}$, a $2.7 \mathrm{~mm}$ cortical screw was used. This technical factor, namely the type of screw to be used, is considered an important factor together with the pedicle dimensions.

Another technical factor to consider is the point of entry for the screws. Jeanneret et al.s [6] entry point was 3 $\mathrm{mm}$ below the inferior articular process; Abumi et al.s [5] entry point was lateral to the midline of the articular mass below the lower margin of the superior articular facet. In our study, the entry point was the outer projection of the pedicle axis which was nearly similar to Abumi et al.'s [5] entry point (Figs. 7, 8).

Two technical considerations would affect the direction of the screws. The first one is the pedicle angle, which 

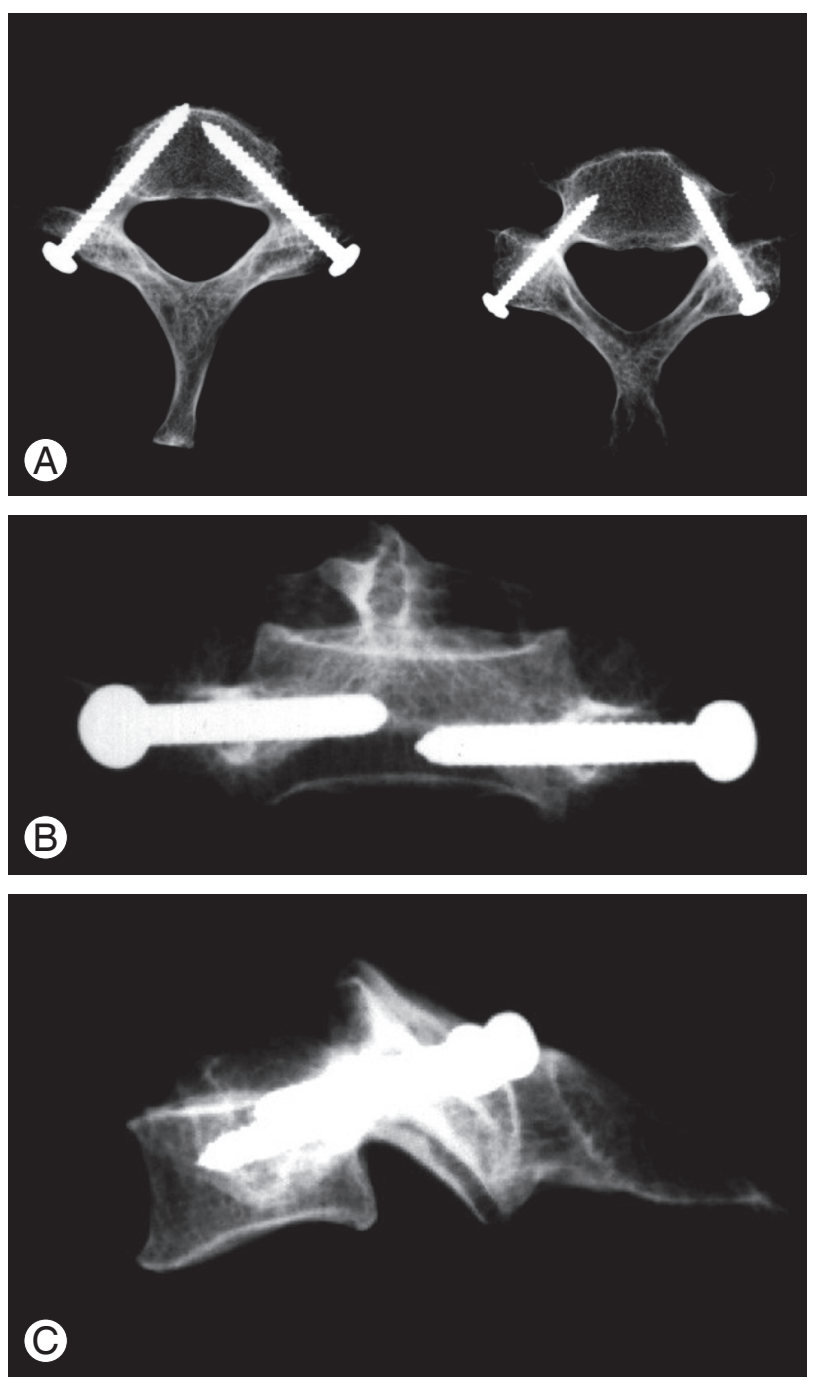

Fig. 7. (A-C) Different X-ray views of the cervical pedicle screws in place.

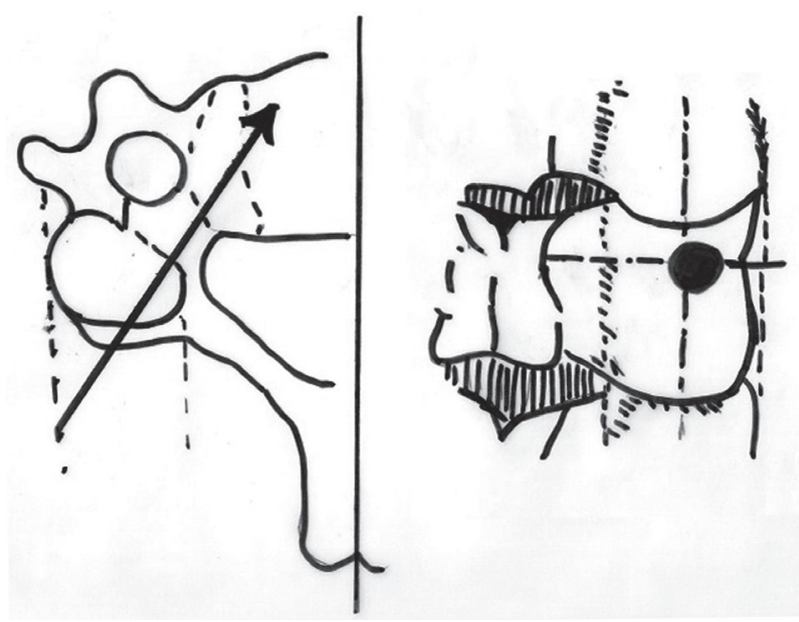

Fig. 8. Screw entry point and direction. ranged in the present study from $33^{\circ}$ to $52^{\circ}$, with a mean of $45^{\circ}$ in the transverse plane relative to the midline. This anatomical finding was identical to that of Jeanneret et al.s [6] and similar to that of Abumi et al.s [5] and Jones et al.s [9]. The second consideration is the pedicle orientation in the sagittal plane which was mostly parallel to the upper end plate.

Regarding the vertebral body depth, screw insertions too deep or few mms beyond the vertebral body should be avoided as it may injure the constrictor of the pharynx above $\mathrm{C} 4$ or the oesophagus below C5 in the median portion. In the present study, the minimum pedicle-axis length was $29.5 \mathrm{~mm}$, which should be kept in mind during screw introductions.

\section{Recommendations of this study}

- Multislice CT examination of bony elements is recommended to determine the pedicle dimensions preoperatively. Patients with very small pedicles should be excluded from the procedure if no adequate screw sizes are available.

- Direct exposure of the pedicle cavity is mandatory by creating a hole at the proposed entry point.

- The use of pedicle probe and image intensifier.

- In cases of facetectomy or laminectomy, the pedicle surfaces (medial, superior and inferior) may be palpated by using a small nerve retractor.

These recommendations are essential to the safety and success of the screw placements.

These recommendations were also stressed by Abumi et al. [5] and Jones et al. [9]. The variability in pedicle morphology and orientation requires careful preoperative assessments to determine the suitability of pedicle screw insertions.

The present study showed that CT measurements of cervical pedicles are accurate and valuable for preoperative plannings of cervical pedicle screw instrumentation. Many cervical pedicles can be suitable sites for posterior instrumentation; however, uniform sized screws cannot be used at all levels. At C3 and C4, care should be taken and smaller screws should be used. However, this procedure is associated with risks of major neurovascular injuries; thus, it requires precise knowledge on the anatomy of the cervical spine, meticulous surgical techniques and performances only by experienced surgeons. 


\section{Conclusions}

Transpedicular screw fixation of the cervical spine appears anatomically promising. However, because it is associated with risks of major neurovascular injuries; it requires precise knowledge on the anatomy of the cervical spine. CT measurements of cervical pedicles appear to be accurate and valuable for preoperative plannings of cervical pedicle screw instrumentation. Anatomic limitations of the procedure should be evaluated preoperatively. Also, further comparative biomechanical studies are needed to precisely assess the stabilizing effects by this procedure.

\section{Conflict of Interest}

No potential conflict of interest relevant to this article was reported.

\section{References}

1. Heller JG, Whitecloud TS. Post-laminectomy instability of the cervical spine: etiology and stabilization techniques. In: Frymoyer JW, editor. The adult spine: principles and practices. New York: Raven Press; 1991. p.1219-40.

2. Kotani Y, Cunningham BW, Abumi K, McAfee PC. Biomechanical analysis of cervical stabilization systems. An assessment of transpedicular screw fixation in the cervical spine. Spine (Phila Pa 1976) 1994;19:2529-39.

3. Perin NI, Cooper PR. Posterior stabilization of the cervical spine using plates and screws. Surgery for spinal cord injuries. New York: Raven Press; 1993. p. 13-22.

4. Heller JG, Estes BT, Zaouali M, Diop A. Biomechanical study of screws in the lateral masses: variables affecting pull-out resistance. J Bone Joint Surg Am 1996;78:1315-21.

5. Abumi K, Itoh H, Taneichi H, Kaneda K. Transpedicular screw fixation for traumatic lesions of the middle and lower cervical spine: description of the techniques and preliminary report. J Spinal Disord 1994;7:19-28.

6. Jeanneret B, Gebhard JS, Magerl F. Transpedicular screw fixation of articular mass fracture-separation: results of an anatomical study and operative technique. J Spinal Disord 1994;7:222-9.
7. Abumi K, Kaneda K. Transpedicular screw fixation for reconstruction of the cervical spine. Proceedings of the 62nd Meeting of the American Academy of Orthopedic Surgeons; 1995 Feb 18; Orland, FL, USA.

8. Abumi K, Kaneda K. Pedicle screw fixation for nontraumatic lesions of the cervical spine. Spine (Phila Pa 1976) 1997;22:1853-63.

9. Jones EL, Heller JG, Silcox DH, Hutton WC. Cervical pedicle screws versus lateral mass screws. Anatomic feasibility and biomechanical comparison. Spine (Phila Pa 1976) 1997;22:977-82.

10. Roy-Camille R, Mazel C, Saillant G, Benazet JP. Rational and techniques of internal fixation in trauma of the cervical spine. In: Errico T, Bauer RD, Waugh T, editors. Spinal trauma. Philadelphia: J.B. Lippincott; 1991. p.163-91.

11. Coe JD, Warden KE, Sutterlin CE 3rd, McAfee PC. Biomechanical evaluation of cervical spinal stabilization methods in a human cadaveric model. Spine (Phila Pa 1976) 1989;14:1122-31.

12. Ulrich C, Woersdoerfer O, Kalff R, Claes L, Wilke HJ. Biomechanics of fixation systems to the cervical spine. Spine (Phila Pa 1976) 1991;16(3 Suppl):4-9.

13. Gill K, Paschal S, Corin J, Ashman R, Bucholz RW. Posterior plating of the cervical spine. A biomechanical comparison of different posterior fusion techniques. Spine (Phila Pa 1976) 1988;13:813-6.

14. Montesano PX, Jauch E, Jonsson H Jr. Anatomic and biomechanical study of posterior cervical spine plate arthrodesis: an evaluation of two different techniques of screw placement. J Spinal Disord 1992;5:301-5.

15. Xu R, Kang A, Ebraheim NA, Yeasting RA. Anatomic relation between the cervical pedicle and the adjacent neural structures. Spine (Phila Pa 1976) 1999;24:451-4.

16. Pech P, Daniels DL, Williams AL, Haughton VM. The cervical neural foramina: correlation of microtomy and CT anatomy. Radiology 1985;155:143-6.

17. Panjabi MM, Duranceau J, Goel V, Oxland T, Takata K. Cervical human vertebrae. Quantitative three-dimensional anatomy of the middle and lower regions. Spine (Phila Pa 1976) 1991;16:861-9.

18. Pal GP, Routal RW. A study of weight transmission through the cervical end upper thoracic regions of the vertebral column in man. J Anat 1986;148:245-61.

19. Karaikovic EE, Daubs MD, Madsen RW, Gaines RW Jr. Morphologic characteristics of human cervical pedicles. Spine (Phila Pa 1976) 1997;22:493-500. 